Editorial

\title{
Turning Point in the Journey of Annals of the National Academy of Medical Sciences (India)
}

\author{
Deep N. Srivastava ${ }^{1}$ \\ 1Department of Radiodiagnosis, All India Institute of Medical \\ Sciences, New Delhi, India
}

Ann Natl Acad Med Sci (India) 2019;55:63-64

It is indeed a matter of pride for the Academy as its official journal Annals of the National Academy of Medical Sciences (India) is venturing into a newly chartered path of a long journey for good. The main aim of a journal is to provide a platform to biomedical scientists and researchers from different fields. It helps in contributing toward the dissemination of health care information at the national and international levels. With this new venture, we hope to take the academic endeavors of publication of the journal to a global level.

National Academy of Medical Sciences (India) was established on April 21, 1961 as a registered society, the "Indian Academy of Medical Sciences" under the Societies Registration Act XXI of 1860, with the objective of promoting the growth of medical sciences. It was inaugurated on December 19, 1961, New Delhi, by Pandit Jawaharlal Nehru, the first Prime Minister of India. The Academy was renamed as "National Academy of Medical Sciences (India)" on November 16, 1976, on the recommendations of a Working Group, set up by the Government of India. The National Academy of Medical Sciences (India) is a unique institution that fosters and utilizes academic excellence as its resource to meet the medical and social goals of the country.

Over the years, the Academy has recognized the outstanding achievements of Indian scientists in the field of medicine and allied sciences and conferred Fellowships and Memberships. Fellows and members are selected through a peer-review process that involves screening by the Advisory Panel of Experts and the Credential Committee elected by the Council and Fellows through voting.

The Academy also elects very eminent persons as Honorary Fellows. The list of eminent persons who have been conferred Honorary Fellowship of the Academy since inception includes Pandit Jawaharlal Nehru, Dr. BC Roy, Maj. Gen. SL Bhatia, Col. RN Chopra, Dr. HM Lazarus, Dr. Jivaraj N Mehta, Dr. AC Ukil, Dr. A. Lakshamanswami Mudaliar, Dr. NA Purandare,
Maj. Gen. SS Sokey, Dr. Sushila Nayar, Smt. Indi-

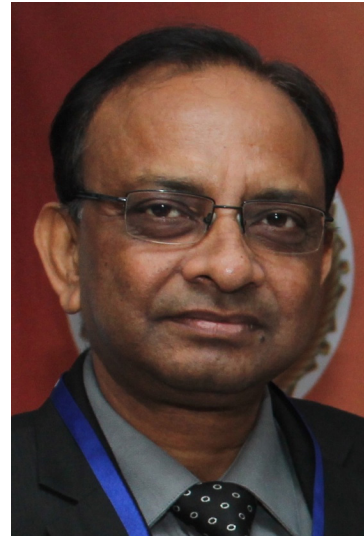

Deep N. Srivastava ra Gandhi, Dr. VTH Gunaratne, Dr. Karan Singh, Dr. Ihsan Dogramaci, Dr. FC Robbins, Dr. U Ko Ko, Dr. Dharmendra, Dr. PK Sethi, Shri PV Narasimha Rao, Prof. Rolf Luft, and Dr. CP Thakur; all luminaries of medical, biomedical, and social fields.

The Academy has been fortunate to have very eminent medical persons, namely, Drs. VR Khanolkar (the first President), CG Pandit, KL Wig, RV Rajam, AK Basu, S Padmavati, PN Chhuttani, BK Anand, B Ramamurthi, BN Sinha, HD Tandon, RK Gandhi, P Siva Reddy, JS Bajaj, Snehalata Deshmukh, BK Sharma, Mathangi Ramakrishnan, NK Ganguly, Hari Gautam, PK Dave, Prema Ramachandran, KK Talwar, CS Bhaskaran, and Mukund S Joshi, as its Presidents.

A special mention is required for Dr. APJ Abdul Kalam, the former President of India, who is considered a scientist par excellence for his contribution to Missile and Rocket technologies. He was a distinguished elected Fellow of the National Academy of Medical Sciences (India) for his unique health care contribution by providing the metal alloy used in missile technology and designing crutches for small children with special needs. Earlier, a 7-year-old child who found it difficult to walk with a 7-kg steel crutch started running after using the crutches designed using Dr. Kalam's metal alloy having 80 times more strength than steel but weighing less than $1.5 \mathrm{~kg}$. This was a unique contribution of Dr. Kalam whose vision made use of the missile alloy for the welfare of children with special walking needs.

This is the second issue of 2019 published by our new collaboration with the world-reputed Thieme Medical and Scientific Publishers. It would be refreshing for the readers to go through the history of the journal. The Annals of the National Academy of Medical Sciences (India) has a long journey dating back to 1964 when the first issue was published. The nomenclature of
Address for correspondence Deep N. Srivastava, MD, MNAMS, MBA, Department of Radiodiagnosis, All India Institute of Medical Sciences, Ansari Nagar, New Delhi 110029, India (e-mail: drdeepsrivastava@rediffmail.com).
DOI https://doi.org/ 10.1055/s-0039-1698612 ISSN 0379-038X.
(C)2019 National Academy of

Medical Sciences (India)
License terms

(요 (1) $\Theta \circledast$ 
the journal at that time was The Annals of the Indian Academy of Medical Sciences after the name of the academy. Henceforth, as the academy was renamed from Indian Academy of Medical Sciences (IAMS) to National Academy of Medical Sciences (India) in November 1976, the journal was also renamed as The Annals of the National Academy of Medical Sciences (India).

One of the goals of National Academy of Medical Sciences (India) is to promote excellence in medical/biomedical/health science education and improve public health. Therefore, our journal acts as a unique multipurpose platform that helps the Academy in subserving its various objectives. The journal caters to both grass root level research and latest updates in medical sciences and technologies. It is an exclusive journal as it has several multispecialty domains and caters to all clinical and paraclinical specialties with cutting-edge research to disseminate knowledge to all and everyone who wants to seek and improve global health.

Different issues of the journal have been getting published online since 2013 and past issues are available since 2005 onward on the website of National Academy of Medical Sciences (India). The past issues from 1964 will be made online in a phased manner. Also, the print copies of these are available at the National Academy of Medical Sciences (India) office and can be obtained on request.

The Editorial Board is constituted by the Council of National Academy of Medical Sciences (India). The council plans to promote international contribution as dissemination of knowledge knows no boundaries. Thieme Medical and Scientific Publishers is an award-winning international medical and science publisher serving professionals for more than 125 years and National Academy of Medical Sciences (India) has full faith that the Annals of the National Academy of Medical Sciences (India) will flourish with its new facelift and achieve its goal of global presence. We hope the readers would whole-heartedly contribute to the growth of the journal.

\section{Conflict of Interest}

None declared.

\section{Acknowledgments}

The help rendered by Dr. Shilpa Sharma, MNAMS, Associate Professor, Department of Pediatric Surgery, AIIMS, New Delhi and Dr. K.K. Sharma by way of providing significant inputs in preparing this editorial is highly appreciated and acknowledged. 